НОВЫЕ ОБРАЗОВАТЕЛЬНЫЕ ТЕХНОЛОГИИ И ИНСТРУМЕНТЫ В ПОДГОТОВКЕ БУДУЩИХ ПЕДАГОГОВ К ПРОФЕССИОНАЛЬНОЙ ДЕЯТЕЛЬНОСТИ В МНОГОКУЛЬТУРНОМ СОЦИУМЕ

\author{
Бойчук Юрий \\ Бережная Светлана \\ Юрьева Екатерина \\ Харьковский национальный педагогический \\ университет имени Г. С. Сковороды \\ https://doi.org/10.52340/idw.2021.535
}

Статья 11 Конституции Украины провозглашает, что государство «содействует консолидации и развитию украинской нации, её исторического сознания, традиций и культуры, а также развитию этнической, культурной, языковой и религиозной самобытности всех коренных народов и национальных меньшинств Украины» [Верховна Рада України, 1996].

По данным Всеукраинской переписи населения [Державний комітет статистики України, 2001a], в 2001 г. в нашей стране жили представители 134 народов [см. табл. 1.1].

Таблица 1.

Наиболее многочисленные этнонациональные сообщества Украины

\begin{tabular}{|c|c|}
\hline $\begin{array}{c}\text { Национальнос } \\
\text { ть }\end{array}$ & $\begin{array}{c}\text { Численнос } \\
\text { ть (лиц) }\end{array}$ \\
\hline Украинцы & 37300000 \\
\hline Русские & 8334100 \\
\hline Белорусы & 275800 \\
\hline Молдаване & 258600 \\
\hline Болгары & 204600 \\
\hline Венгры & 156600 \\
\hline Румыны & 151000 \\
\hline Поляки & 144100 \\
\hline Евреи & 103600 \\
\hline Армяне & 99900 \\
\hline Греки & 91500 \\
\hline Татары & 73300 \\
\hline Цыгане (ромы) & 47600 \\
\hline Азербайджанцы & 45200 \\
\hline Грузины & 34200 \\
\hline Немцы & 33300 \\
\hline Гагаузы & 31900 \\
\hline
\end{tabular}


из них на Харьковщине - представители 111 этносов [Державний комітет статистики України, 2001b] [см. табл. 2].

Таблиияа 2

Этнонациональная структура населения Харьковской области

\begin{tabular}{|c|c|}
\hline Национальность & $\begin{array}{l}\text { Численность } \\
\text { (лиц) }\end{array}$ \\
\hline Украинцы & $\begin{array}{l}20487 \\
00\end{array}$ \\
\hline Русские & 742000 \\
\hline Белорусы & 14700 \\
\hline Евреи & 11500 \\
\hline Армяне & 11100 \\
\hline Азербайджанцы & 5600 \\
\hline Грузины & 4400 \\
\hline Татары & 4200 \\
\hline Молдаване & 2500 \\
\hline Вьетнамцы & 2400 \\
\hline Ромы & 2300 \\
\hline $\begin{array}{l}\text { Представители } \\
\text { ещё } 100 \text { этносов }\end{array}$ & \\
\hline
\end{tabular}

Концепция национально-патриотического воспитания в системе образования Украины (в редакции от 29.07.2019 г.) основывается на признании того, что в стране складывается единая украинская политическая нация, поэтому национальнопатриотическое воспитание «не должно прививать идеи культурного империализма, то есть способа созерцания мира только глазами собственной культуры» [МОН України, 2019: 2]. Концепция «исходит из идеи объединения различных народов, национальных и этнических групп, проживающих на территории Украины, вокруг идеи украинской государственности, украинского гражданства... Украинское государство отрицает любые формы дискриминации, поддерживая все языки и культуры, подвергшиеся такой дискриминации во времена колониальной зависимости Украины»[Там же]. Поэтому крайне важно обеспечить осознание молодым поколением реалий культурного разнообразия, толерантное отношение к различным культурным ценностям, понимание исторических истоков региональных и национально-языковых особенностей Украины.

Выполнить этот актуальный социальный заказ может только педагог, способный к эффективной профессиональной деятельности в условиях культурно разнообразного социума, обладающий межкультурной компетентностью.

Межкультурное образование в Украине опирается на достаточно разработанную законодательно-нормативную и концептуальную базу, основу которой составляют: Конституция Украины, Законы Украины «Об образовании», «О высшем образовании», Концепция национально-патриотического воспитания в системе образования Украины, Долгосрочная стратегия развития украинской культуры - стратегия реформ и другие документы. При этом упомянутые законодательно-нормативные акты и концепции опираются на наработки 
многочисленных международных организаций, в частности ООН, ЮНЕСКО, ЮНИСЕФ, Совет Европы: Белая книга по межкультурному диалогу «Жить вместе в равенстве и достоинстве», Декларация о правах лиц, принадлежащих к национальным или этническим, религиозным и языковым меньшинствам, Конвенция о правах ребёнка, Рамочная Конвенция Совета Европы о значении культурного наследия для общества, ряд Рекомендаций Всемирной конференции по политике в сфере культуры, Хартия Совета Европы по Образованию для демократического гражданства и Образованию по правам человека, другие документы.

Теоретические и методические основы подготовки молодого поколения к жизни в условиях культурного разнообразия начали закладываться ещё в 80-х гг. XX века. На сегодня достаточно детально разработаны:

- концепции полиэтнического, кросс-культурного, многокультурного, мультикультурного, межкультурного образования [Banks, 2009; Barrett, Byram, Lázár, Mompoint-Gaillard \& Philippou, 2013; Palaiologou \& Gorski, 2017 и др.];

- содержание, методики и технологии подготовки учителей к работе в условиях многокультурности [Gorski, 2009; Hollins \& Guzman, 2005; Leutwyler, Petrović \& Mantel, 2012; Nieto, 2009; Zlatković \& Petrović, 2016; Юp'сва, 2016 и другие];

- $\quad$ концепция и практики формирования межкультурной компетентности и её отдельных компонентов [Hrvatić \& Piršl, 2007; Mikeladze \& Makaradze, 2016; Микеладзе, 2012; Petrović, Jokić \& Leutwyler, 2016; Petrović, Zlatković, Jokić, Erić, Dimitrijević \& Leutwyler, 2016 и др.];

- диагностический инструментарий для определения степени сформированности компонентов межкультурной компетентности [Fantini, 2009; Van Der Zee \& Van Oudenhoven, 2000 и др.].

Ранее мы рассматривали философские подходы к трактованию феномена мультикультурализма [Бережна, 2016], теоретические и практические аспекты компетентностной образовательной парадигмы [Бойчук \& Таймасов, 2015; Юр'сва \& Тіщенко, 2014 и др.], исследовательский и образовательный потенциал сравнительного подхода [Бережна, 2011; Юр'єва, 2016 и пр.], специфику использования образовательных технологий, в том числе цифровых, в непрерывном педагогическом образовании [Бойчук \& Казачінер, 2020; Танько, Тарарак \& Юр'єва, 2019 и др.].

Исходим из того, что межкультурная компетентность обеспечивает педагогу способность осознавать и уважать культурное многообразие современного украинского общества, понимать его ценность как ресурса для развития личности и социума, использовать на практике образовательно-воспитательный и социализующий потенциал культурного разнообразия.

Нами обоснована структура этой компетентности, которая содержит три компонента: личностно-психологический, когнитивный, деятельностный [Юр' $\mathbf{\text { (Ba }}$ \& Tiщенко, 2014]. Личностно-психологический компонент должен быть представлен толерантностью к проявлениям инокультурности, направленностью на толерантное взаимодействие с представителями различных культур, стремлением к самоопределению в сфере межкультурной коммуникации [Юр'єва, 2016: 205]. Когнитивный компонент межкультурной компетентности определяет теоретическую основу профессиональной деятельности учителя и воспитателя в условиях этнокультурного многообразия общества, а именно - знания: сути 
межкультурного образования молодого поколения, его теории, истории развития и современного состояния, а также основных отечественных и международных нормативных документов, регламентирующих осуществление межкультурного образования в Украине [Юр'єва, 2016: 202-203, 205]. Деятельностный компонент рассматриваемой компетентности предполагает сформированность умений: работать с многокультурным детским коллективом, индивидуально работать с детьми - представителями разных этносов и культур, сотрудничать с многокультурным социальным окружением, в частности, с родителями учащихся и представителями общественных организаций национальных меньшинств [Юр'сва, 2016: 203, 206].

Нами разработана и на протяжении 20 лет апробирована в образовательном процессе Харьковского национального педагогического университета имени Г. С. Сковороды модель формирования межкультурной компетентности будущих учителей общеобразовательных школ и воспитателей дошкольных учреждений [Юр'сва, 2016].

Модель предусматривает конструирование содержания профессиональной подготовки на основе сравнительно-сопоставительного ознакомления будущих учителей и воспитателей с традиционной, в частности, педагогической культурой разных народов, реализацию этого содержания в процессе изучения курса сравнительной этнопедагогики и интеграцию с программами других дисциплин учебного плана, педагогических практик, внеучебной и научно-исследовательской деятельности студентов.

Также модель формирования межкультурной компетентности будущих учителей и воспитателей предусматривает отбор и применение широкого спектра инновационных форм, методов и приёмов работы: интерактивных (для приобретения умений устанавливать взаимодействие, вести диалог, в частности, с представителями различных культур), тренинговых (элементы тренингов толерантности), игровых («Паутина предрассудков», «Метки», «Подарки», «Две культуры», «Облака», «Встреча цивилизаций» и т. п.), проектных (разработка сценариев детских и молодёжных праздников на основе народных традиций), составление картотек воспитательных мероприятий для ознакомления дошкольников и учащихся школ с культурами разных народов, анализ особенностей содержания и форм гражданского и межкультурного воспитания в школах национальных меньшинств, разработку анкет для родителей и т. п.), направленных на комплексное формирование всех компонентов межкультурной компетентности будущих учителей и воспитателей - личностно-психологического, когнитивного, деятельностного.

Кроме того, в процессе реализации модели активно используем потенциал образовательной среды межкультурного общения, создание которой в педагогическом университете стало возможным благодаря международному контингенту студентов и аспирантов из Азербайджана, Алжира, Армении, Болгарии, Вьетнама, Грузии, Ирана, КНР, Республики Конго, Республики Корея, Таджикистана, Туркменистана и других стран. Также в ХНПУ имени Г. С. Сковороды действуют израильский, иранский, китайский, турецкий, украинский культурные центры, два региональных центра - польского языка, культуры и науки и японской культуры и образования.

В процессе реализации модели формирования межкультурной компетентности организовываем взаимодействие студентов, учёных, педагогов, общественных 
организаций национальных меньшинств с целью исследования традиций воспитания в разных культурах и творческого использования опыта народной педагогики в образовательном процессе современных учебных заведений. Методика работы предусматривает проведение практических занятий в интерактивном формате «Живой библиотеки», усиление эмоционального воздействия занятий применением упражнений, связанных с необходимостью делать нравственный выбор в ситуациях межкультурных контактов - моральных дилемм (дилемма Хельги, «Хорошие соседи», «Вымершее село», «Не хочу принимать в этом участие», в основу которых положены реальные жизненные ситуации, связанные с большими трагедиями XX века - геноцидом армян, Голодомором, Холокостом, депортацией крымских татар и т. п.) [Ленчовська, Крейдерман, \& Грінберг, 2010: 22-27], работу с медиаресурсами (фильмы фестиваля Docudays, мультфильмы проекта «Колыбельные мира», ролики видеопроекта 24 телеканала «Сделано в Украине»и т. п.), а также привлечение студентов к проектно-поисковой работе этнопедагогического содержания (сбор информации о традициях воспитания в разных культурах от их носителей).

Карантин, установленный в связи с пандемией COVID-19, вынудил перейти на дистанционную форму работы. В условиях дистанционного обучения традиционный методический инструментарий оказался недостаточно действенным, поскольку не мог в полной мере обеспечить формирование личностнопсихологического компонента межкультурной компетентности будущих педагогов, a также выработку умений и приобретение опыта, лежащих в основе её деятельностного компонента.

В 2020/2021 уч. году, в дополнение к Moodle, были использованы виртуальные интерактивные доски Padlet, Google Jamboard, cервис для создания презентаций и мгновенных опросов Mentimeter, онлайн инструмент для создания интерактивных игр Wordwall и др.

Ha Padlet заблаговременно размещены все документы, с которыми должны ознакомиться студенты: рабочая программа дисциплины, нормативные документы, электронные версии рекомендованных источников, ссылки на рекомендуемые видеофайлы и пр. В течение семестра рекомендованные для ознакомления материалы на доске Padlet обновляются (например, после принятия новой редакции был заменён текст Базового компонента дошкольного образования) и добавляются новые.

Наряду с этим мы широко используем Padlet для групповой работы студентов во время занятий. Zoom позволяет объединять участников в группы и разводить по отдельным сессионным залам. Каждая такая группа создаёт на доске Padlet свою заметку, в которой выполняет практическое задание. После окончания групповой работы и входа всех участников в общий зал, каждая группа отчитывается о своих наработках, отвечает на вопросы других участников. Студенты имеют возможность в любое удобное время работать на доске Padlet: размещать выполнены домашние задания, читать или просматривать рекомендуемые источники, комментировать работы других студентов.

Доску Jamboard удобнее использовать в случаях, когда необходимо передвигать, систематизировать, размещать в определённом порядке стикеры с текстом или другие заранее подготовленные объекты. Благодаря таким перемещениям можно даже выполнять упражнения типа «Займи позицию», что важно для работы по формированию личностно-психологического компонента 
межкультурной компетентности.

Онлайн инструмент для создания презентаций и проведения мгновенных опросов Mentimeter широко используем на этапе мотивации студентов и настройки на работу, для актуализации опорных знаний, а также в конце занятия для подведения итогов и рефлексии. Стоит отметить, что Mentimeter не идентифицирует участников опроса. Такая анонимность является удобной для студентов, поскольку позволяет свободно выражать собственное мнение, не опасаясь получить низкую оценку. В то же время Mentimeter даёт возможность определить готовность группы к работе, отследить динамику усвоения материала, выяснить настроение группы и т. п. По нашим наблюдениям, из всех многочисленных вариантов опросов студентам больше всего нравится создание облаков слов.

Wordwall - сервис для создания интерактивных упражнений и материалов для распечатки, предоставляет многочисленные шаблоны и готовые упражнения, которые можно редактировать. Большинство шаблонов доступны в интерактивном виде, а также в версии для печати. Интерактивные упражнения можно воспроизводить на любом веб-устройстве: компьютере, планшете, телефоне или интерактивной доске. Студенты могут работать с упражнениями не только в собственных аккаунтах, но и анонимно, переходя по предоставленным преподавателем ссылкам. Единственный обнаруженный нами недостаток онлайн инструмента Wordwall - ограниченное количество упражнений, которые можно создать, используя бесплатную версию - всего пять.

03.02.2021 г. на заседании Комитета Верховной Рады по вопросам образования, науки и инноваций Министр образования и науки Сергей Шкарлет отметил: «Диджитализация всех сфер общественной жизни является актуальным направлением не только из-за пандемии, но и вообще в связи с глобальными трендами сегодняшнего дня и общегосударственной политикой в отношении вектора цифровой трансформации государства» [МОН України, 04.02.2021]. При этом к основным мерам, призванным обеспечить реализацию цифровой трансформации в системе образования, министр отнёс такие шаги: «утвердить Концепцию цифровой трансформации образования и науки Украины; обеспечить участников образовательного процесса электронными образовательными ресурсами; создать условия для повышения квалификации педагогических работников учебных заведений в сфере информационно-цифровой компетентности»[Там же].

В разработке и внедрении онлайн инструментов сейчас нуждаются не только общее среднее и высшее образование, а также и дошкольное, и последипломное педагогическое образование, и сотрудничество учреждений образования с семьями учащихся и другими социальными институтами, и психолого-педагогическое просвещение широкой общественности.

\section{Библиография:}

Бережна С. В. (2011) : Сучасний стан та перспективи порівняльного методу в гуманітарній освіті: компаративний аналіз // «Філософія і політологія в контексті сучасної культури», № 2. 35-43.

Бережна С. В. (2016) : Феномен мультикультуралізму в постмодерні // «Вісник Харківського національного педагогічного університету імені Г. С. Сковороди. Філософія», № 47(2). 40-46.

Бойчук Ю. Д., \& Казачінер О. С. (2020) : Розвиток інклюзивної компетентності вчителів у системі післядипломної освіти засобами ІКТ // «Освіта дорослих: теорія, досвід, перспективи», №. 2. 66-75.

Бойчук Ю. Д., \& Таймасов Ю. С. (2015) : Компетентнісна парадигма в сучасній вищій професійній освіті // 
«Новий Колегіум», № 1. 38-44.

Верховна Рада України. (1996) : Конституція України. URL: https://zakon.rada.gov.ua/laws/show/254к/96вр\#Техt

Державний комітет статистики України. (2001a) : Національний склад населення // «Про кількість та склад населення України за підсумками Всеукраїнського перепису населення 2001 року». URL: http://2001.ukrcensus.gov.ua/results/general/nationality/

Державний комітет статистики України. (2001b) : Національний склад населення // «Про кількість та склад населення Харківської області за підсумками Всеукраїнського перепису населення 2001 року». URL: http://2001.ukrcensus.gov.ua/results/general/nationality/kharkiv/

Ленчовська А., Крейдерман К., \& Грінберг М. (2010) : Полікультуріка: як організувати виховання міжкультурної толерантності у школі та позашкільній діяльності. Майстерня книги. Київ.

Микеладзе М. (2012) : Внедрение европейского опыта в сферу воспитания демократической гражданственности в Грузии // «Историко-филологические изыскания». Санкт-Петербургский государственный университет, Государственный университет Шота Руставели, издательство «Универсал».

МОН України. (04.02.2021) : Цифрова трансформація освіти і науки є однією з ключових цілей МОН на 2021 рік, - Сергій Шкарлет. URL: https://mon.gov.ua/ua/news/cifrova-transformaciya-osviti-i-nauki-yeodniyeyu-z-klyuchovih-cilej-mon-na-2021-rik-sergij-shkarlet

МОН України. (2019) : Концепція національно-патріотичного виховання в системі освіти України : Додаток до наказу Міністерства освіти і науки України від 16.06.2015 № 641 (у редакції наказу Міністерства освіти і науки України від 29.07.2019 р. № 1038). URL: https://zakon.rada.gov.ua/rada/show/v064172915\#Text

Танько Т., Тарарак Н., \& Юрьева Е. (2019) : Новые ценности образования и новые образовательные технологии в профессиональной подготовке будущих учителей и воспитателей // bsةgзбоgқм

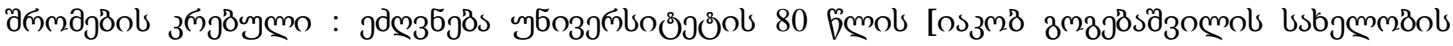

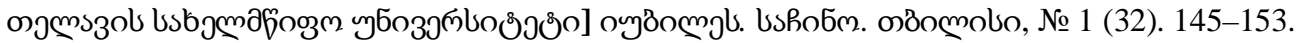

Юр'сва, К. А. (2016) : Порівняльна етнопедагогіка в професійній підготовці майбутніх учителів початкових класів. Видавець Рожко С. Г. Харків.

Юр'єва, К. А., \& Тіщенко, О. М. (2014) : Компетенція, компетентність, міжкультурна компетентність учителя: сутність і зміст // «Засоби навчальної та науково-дослідної роботи», № 42. 169-182.

Banks, J. A. (2009) : Diversity and Citizenship Education in Multicultural Nations // „Multicultural Education Review”, № 1(1). 1-28.

Barrett, M., Byram, M., Lázár, I., Mompoint-Gaillard, P., \& Philippou, S. (2013) : Developing Intercultural Competence through Education. Council of Europe Publishing. Strasbourg.

Fantini, A. E. (2009) : Assessing intercultural competence // „The SAGE Handbook of Intercultural Competence”. Thousand Oaks : SAGE Publications. 456-476.

Gorski, P. (2009) : What we're teaching teachers: An analysis of multicultural teacher education coursework syllabi // ,Journal of Teaching and Teacher Education”, № 25(2). 309-318.

Hollins, E. R., \& Guzman, M. T. (2005) : Research on preparing teachers for diverse populations // „Studying teacher education: The report of the AERA Panel on Research and Teacher Education". Lawrence Erlbaum. Mahwah, NJ. 477-548.

Hrvatić, N., \& Piršl, E. (2007) : Interkulturalne kompetencije učitelja // „Kompetencije i kompetentnost učitelja”. Učiteljski fakultet. Osijek ; Kherson State University. Kherson. 221-230.

Leutwyler, B., Petrović, D., \& Mantel, C. (2012) : Constructivist Foundations of Intercultural Education: Implication for Research and Teacher Trainging // „International Perspectives on Education”. Bulgarian Comparative Education Society. Sofia. 111-118.

Mikeladze M., \& Makaradze N. (2016) : Stereotypes as One of the Obstacles in Developing Civic Consciousness // „Active Issues on Teaching and Upbringing”. The works of 7th international scientific-methodological conference. Kutaisi.

Nieto, S. (2009) : The Light in their Eyes: Creating Multicultural Learning Communities. Teachers College Press. New York.

Palaiologou, N., \& Gorski, P. C. (2017) : The evolution of intercultural and multicultural education: scholarship and practice for new sociopolitical and economic realities // „Intercultural Education”, № 28(4). 353-355.

Petrović, D. S., Jokić, T., \& Leutwyler, B. (2016) : Motivational aspects of teachers' intercultural competence: Development and psychometric evaluation of new scales for the assessment of motivational orientation // „Psihologija”, № 49(4). 393-413.

Petrović, D., Zlatković, B., Jokić, T., Erić, M., Dimitrijević, B., \& Leutwyler, B. (2016) : Competences for 
intercultural education: Conceptualization and Empirical Findings // „InPACT 2016 - International psychological applications conference and trends". Book of Proceeding. Lisbon. 355-359.

Van Der Zee, K. I., \& Van Oudenhoven, J. P. (2000) : The Multicultural Personality Questionnaire: A multidimensional instrument of multicultural effectiveness // „European journal of personality”, № 14(4). 291-309.

Vranješević, J. (2014) : The main challenges in teacher education for diversity // „Zbornik Instituta za pedagoška istraživanja”, № 46(2). 473-485.

Zlatković, B., \& Petrović, D. (2016) : Interkulturalno obrazovanje budućih učitelja u Srbiji’ // „Interkulturalno obrazovanje u Srbiji - Regulativni okvir, stanje i mogućnosti za razvoj”. Centar za obrazovne politike. Beograd. 76-87.

\title{
New Educational Technologies and Tools in Future Teachers' Preparing for Professional Activities in a Multicultural Society
}

Boychuk Yuriy, Berezhna Svitlana, Yuryeva Kateryna H. S. Skovoroda Kharkiv National Pedagogical University

\begin{abstract}
Ethno-cultural diversity of the population of Ukraine actualizes the problem of preparing future teachers and educators for professional activities in a multicultural society. The legislative, normative, and conceptual framework of intercultural education in Ukraine is listed. The achievements of international organizations have been taken into account and creatively developed: UN, UNESCO, UNICEF, The Council of Europe. The author's approach to the interpretation of the essence of intercultural competence is revealed, which provides the teacher with the ability to understand and respect the cultural diversity of modern Ukrainian society, understand its value as a resource for the development of personality and society, and use in practice the educational and socializing potential of cultural diversity. The structure of the intercultural competence is outlined, which combines personal-psychological, cognitive, procedural-activity components. The model of the formation of future teachers' intercultural competence was developed and implemented at the H.S. Skovoroda Kharkiv National Pedagogical University. The model assumes the construction of the content of the process of forming intercultural competence on the basis of a comparative acquaintance of future teachers with the traditional culture of different peoples and its implementation in the educational process, pedagogical practices, extracurricular and research activities of students; the use of innovative forms, methods and techniques of work: interactive, training, game, project; purposeful impact on the emotional sphere of the student's personality (work with moral dilemmas and multimedia resources); creation of an educational environment for intercultural communication in a pedagogical university. The media resources used in the process of forming the intercultural competence of future teachers (films of the Docudays festival, cartoons of the "Lullabies of the World" project, clips of the video project "Made in Ukraine", etc.), as well as digital tools (virtual interactive whiteboards Padlet, Google Jamboard, service for creating presentations and instant polls Mentimeter, an online tool for creating interactive Wordwall games).
\end{abstract}

Ключевые слова: межкультурная компетентность, профессиональная подготовка, модель, сравнительный метод, цифровые инструменты.

Key words: intercultural competence, professional training, model, comparative method, digital tools. 